\section{OPEN ACCESS}

Volume: 7

Issue: 1

Month: July

Year: 2019

ISSN: $2321-788 \mathrm{X}$

Received: 13.05.2019

Accepted: 23.06.2019

Published: 01.07.2019

Citation:

Dharmalingam, B., et al. "Dance Form

of Karagattam-The Regional Folk Dance in Tamil Nadu." Shanlax International Journal of Arts, Science and Humanities, vol. 7, no. 1, 2019, pp. 71-75.

DOI:

https://doi.org/10.34293/ sijash.v7i1.485

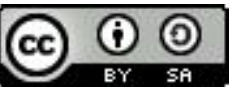

This work is licensed under a Creative Commons Attribution-ShareAlike 4.0 International License

\title{
Dance form of Karagattam - The Regional Folk Dance in Tamil Nadu
}

\section{B.Dharmalingam}

Professor and Head i/c, Department of Fine Arts

Alagappa University, Karaikudi, Tamil Nadu, India

\section{M.S.Kanagathara}

Teaching Assistant, Department of Fine Arts

Alagappa University, Karaikudi, Tamil Nadu, India

\section{M.Muthumari}

Research Assistant Department of Fine Arts

Alagappa University, Karaikudi, Tamil Nadu, India

\section{P.Avanthraj}

Teaching Assistant, Department of Fine Arts

Alagappa University, Karaikudi, Tamil Nadu, India

\section{Abstract}

India is a land of varied cultures and traditions, diversities in all spheres which make the Indian culture quite unique. Indian folk and tribal dances are the product of different socio-economic set up and traditions evolved over ages.. In India, we have festivals and celebrations virtually every day and dances are performed to express joy and festivity. This has added to the richness of Indian culture. Since every festival is accompanied by celebration of folk and tribal dances and almost all of them have continually evolved and improvised.

In India, we have festivals and celebrations virtually every day and dances are performed to express joy and festivity. This has added to the richness of Indian culture. Since every festival is accompanied by celebration of folk and tribal dances and almost all of them have continually evolved and improvised. Folk dances are performed for every possible occasion - to celebrate the arrival of season's birth of a child, a wedding and festivals which are plenty with minimum of steps or movements. Indian folk dances are full of energy vitality. Some dances are performed separately by men and women while in some performances, men and women dance together.

Keywords: Regional Dance, Karagattam, Forms of karagattam

\section{Introduction}

Folk forms evolved along with the evolution of man. This form grew among humanity similarly as the growth of beliefs and habits among mankind. Folk arts can be expressed his brotherhood, becoming one with nature and the expressing the inner feelings of mankind and its beauty and revelation. The folk arts are not written down in history as literature. There is no author or any particular performed to express joy as well as sadness. ( Ananthi Ramachandhiran , 1962) Without giving any importance to principles and lodes the tribal people expressed their artistic feeling through this art taking examples and theme and activities from nature for their idea of expression the people who found Who Found real happiness in work and toil, sang interesting song as a joyous expression the physical tiredness due to hard work. These folk art forms were preserved in every temple which turned into art museum in every village in Tamil Nadu. The dance along ith story became Koothus which evolved into drama. (Krishna Chaitanya, 1990). 

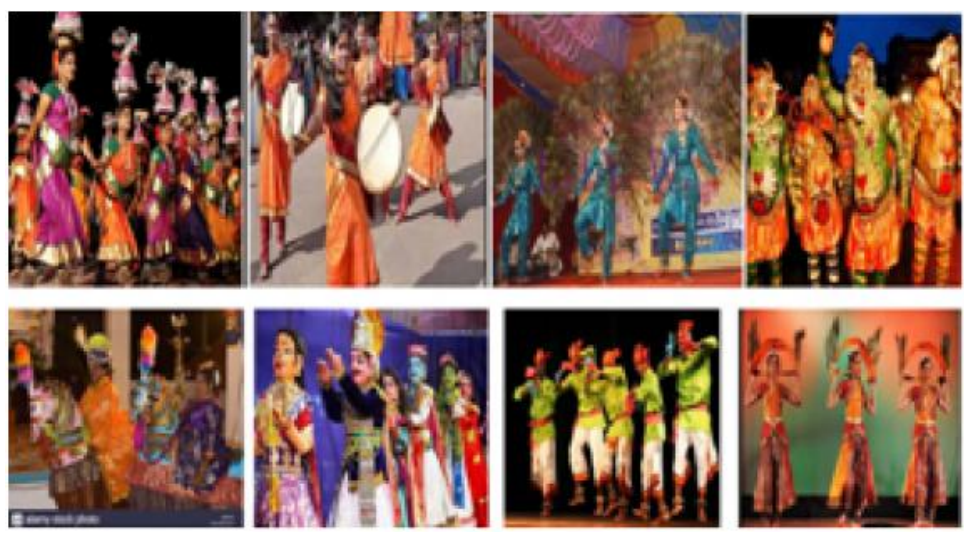

Figure 1: Tamil Nadu Regional Folk Dances

Folk arts based on the properties used (Wikipedia.org)

- Karagattam

- Thorpavai Koothu

- Marappavai Koothu

- Poikkaal kudhirai attam

- Kavadi attam

- Kudhirai attam

Folk arts based on the musical instruments

- Udukkai pattu

- Vilupattu

- Maguda attam

Folk arts based on disguise

- Kuyil attam

- Mayil attam

- Kavadi attam

- Kuravan , kurathi attam

- Puliyattam

- Pagal vesham

- Therukoothu

\section{Karagattam}

A dance which is performed with a small pot on the head is called karagatam. Karagattam implies a small pot carried by rishis, ice cube water drop Ganges or flower pot (Gunasekaran K.A, 1993). Karagattam is born from worship of Mariamman. Like 'Bharathanatyam' follows a particular structured design; our regional folk dance 'karagattam' also performed in a structured way which is not known to many of us. Let us see the same in detail. Karagattam is regional folk dance in which the dancer keeps a pot of different kinds on his/her head and performs the dance. (Without letting the pot fall down this is not actually tied up with anything)

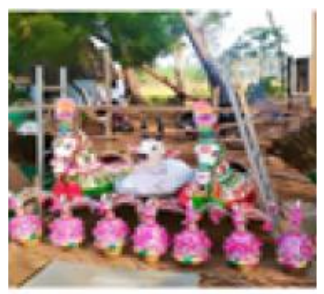

Figure 2: Karagattam

\section{Karagattam is of two types}

- Karagattam intended for worship

- Karagattam performed as professional art

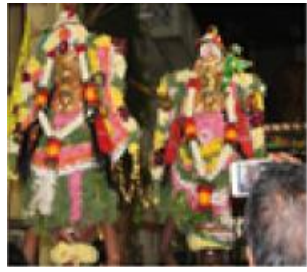

Figure 3: Sakthi Karagam

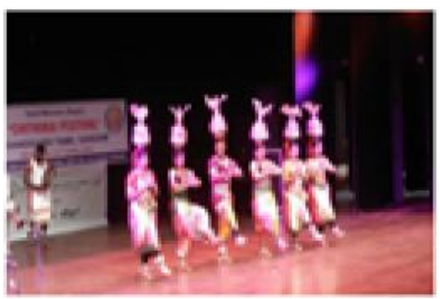

Figure 4: Aata Karagam 


\section{Karagattam as Ritual Performance}

This is called as "Sakthi Karagattam" or Amman karagattam. A small pot is filled with water and closed by coconut. The coconut is decorated with flowers and a lemon is kept on top of coconut. This is called Karagattam. (Krishnaiyer. E, 1956)

It is believed that the Karagattam holds the sea and holy rivers within itself. So these who worship god and when the water in the Karagattam is felt on the head feel that they get all the fruits of taking bath in the holy rivers.

After a strong fest or deep worship to the goddess, the person who performs karagattam is taken to the temple in a musical procession of drums and band. From there he is taken to the banks of the river by the priest and the crowd. There the pot is filled with water and after placing the coconut on it a parrot doll is interested in the karagattam. This decoration of the karagattam is called the growing of karagattam is karagattam valarthal.

The performers of karagattam wear dhoti dipped in turmeric applying sandal paste all over the body with as his on the forehead and body wearing a flower garland and further decorate themselves with flower strings on the hands. Sometimes they carry a sword in one hand. By beating the drums the performer is led to a state of trans and then priest will place the karagattam on the dancer's head (Sunil Shukla, 2017). The dancer usually does not hold the karagattam (Exemption is made in certain places). He will then be led in procession along with drum heat. During that time the women wash the feet of the performer and get his blessings.

People believe that a karagattam dancer predicts some future incident though the power of Amman and that the prediction will be realized. The performer will then go back to the temple and removes the karagattam and he is not supposed to take it out any time before that.

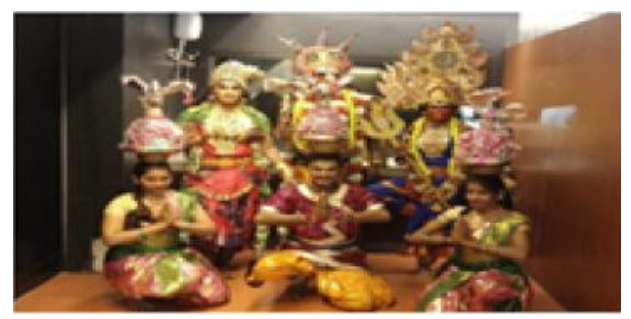

Figure 5: Karagata Artist

\section{They are classified into 4 types generally}

- Thondi karagattam

- Agni karagattam

- Adukku karagattam

- Poo karagattam

\section{Thondi karagattam}

This is one type in which a soil pot filled with neem leaves with stems is used by the dancer.

\section{Agni karagattam}

In this a soil pot with lot of holes (the holes are put in the pot when it is in wet condition) is used in which a lamp is kept inside and the dancer performs the dance keeping this lamped pot over his head. And this particular from has adapted many changes according to today's scenario.

\section{Adukku karagattam}

While it is surprising to see a dance is with an untied pot over the head, this type is even more beautiful to see that more than two pots are kept on the head one over the other pot. And the fact is that none of them is tied up with each other.

\section{Poo karagattam}

Poo karagattam in the type the pot decorated with full of flowers around is used by the dancer. Initially this folk art was indented to perform worshiping the god. Later on there are so many changes occurred in the art and it is fully commercialized now a day, and is performed as a entertainment event.

\section{Margam in Karagattam}

If we look into the structure further, we can observe the beauty of its design that it has various steps in built.

\section{The structure of karagattam}

- Kumba Attam

- Mookaayi Vesham

- Kuravan-keerthi vesham

- Nalla Thangaal kathai

- Pei Aattam

- Mangalam 


\section{There are different forms in karagattam Kumba Aattam}

This is a form in which either a coconut or the flowers of coconut tree which is called 'Thennam paalai' in Tamil, is kept in a soil pot which the dancer uses while performing this dance form.

As we saw in Bharathanatyam in this dance also the dancer starts with saluting the Guru first, the God and then the audience finally, the concept of this item will normally be like,

- Praising the Lord

- Narrating the history of place

- Praising the patriotic leaders

- Creating social awareness

\section{Mookkayi vesham}

This item id followed by 'Kumba attam'. In this a male or a female appears on the stage in an elderly get up and coveys the concept of the dance in the form of proverbs. The interesting part here is that the makeup, the slang used, the action everything will be relevant to the region it is performed.

\section{Kuravan-kurathi Aattam}

The next dance is called kuravan - kurathi aatam. In this, a couple with kuravan-kurathi make up will perform on the stage with different concepts. They show their talents, humorously, cleverly to exhibit their knowledge about the current affairs.

In the past, the concept was covered with the concept politics, social awareness and different current affairs etc., but now a day, so many changes have been made in the concept and in this event.

\section{Nalla Thangaal Kathai}

This is considered as the main concept of this karagattam. Through this story, the life style of the general public, habits, civilization, social degradation, disbeliefs are well depicted using dance forms. Usually there is a good acceptance to this part of karagattam. Because, of its simple nature and easy to understand expressions and elegant design of this dance.

\section{Pei Aattam}

This is a thrilling item of karagattam where in the dance movements will be very fast and in jumbling form. The person who plays the role usually predicts the good and bad events that are going to happen in the near future. The people will trust in their words and believe that God itself convey something through these people. And this event is called as 'Kuri solluthal' or 'Arul vakku' in Tamil in different places.

And it is also believed that of these so called 'God blessed people 'give assurance then there will be a good rainfall as well. A famous karagatta dancer Mrs. Uma said in an in review that, this is a very reason in some places where there is a scarcity of water, because of no rain, the village people are deliberately willing to perform 'karagattam' for the wellbeing of their village (Personal interview with Uma, 2019).

\section{Mangalam}

Mangalam is a final item in these events. The concept of this event is nothing but 'thanks giving'. The dancer thanks Guru, God, the art, the earth, the guests, the audience everybody including the organizers in dance format and completes the event with the good satisfied response from the public.

\section{Conclusion}

In dance, margam means the path, way, the procedure, the structure, the principals, the ethics and so on.it is one full definite course where in dance items are performed in a traditional order A Margam in dance means the procedure in which a dance is to be performed.

- Any art is not just an entertainment oriented. It depends the likeness of the society, socioeconomic conditions culture and civilization of that particulars place.

- Karagattam was initially designed and formed for worshipping God. The 'Karagattam' dancers generally precede the God's procession in a temple festival.

- The reason behind performing karagattam with keeping a pot over the head

It is believed that the gateway of entering positive energy of this universe into own body is the center part of our head. This is the strong reason why the millets, coconut or its flower (Thennam paalai) are kept in the soil pot which is used by the person 
performing 'karagattam'.

Once again we would like to emphasis the point that 'karagattam' is an eminent dance format which has a structured design with aesthetic sense and meaningful. But the social degradation does not spare this excellent art even. It is our very responsibility to encourage and safeguard our traditional folk arts such as karagattam to take it forward to our next generation.

\section{References}

Anathiramachandhiran. Nam Naattu Nadanankal Paari Nilayam, Chennai, 1962.
Chaitanya, Krishna. Arts of India, Abhinav Publications, 1990.

Gunasekaran KA. Nattupura Nigal Kalaigal, N.C.P.H (Pvt. Ltd) Chennai, 1993.

https://en.wikipedia.org/wiki/Indian_classical_ dance

Interview with Ms.Uma Director Kodangi kalaikulu, Srivilliputhur (Folk dancer) dated 26.04.2019 Krishnaiyer, E. Karagam Aduthal, kalai kalanchiyam, 1956, Part -111.

Shukla, Sunil. Most Famous Traditional Folk Dances of Indian States Author, 2017.

\section{Author Details}

Dr.B.Dharmalingam, Professor and Head i/c, Department of Fine Arts, Alagappa University, Karaikudi, Tamil Nadu, India.Email ID: dfaauni@gmail.com

Dr.M.S.Kanagathara, Teaching Assistant, Department of Fine Arts, Alagappa University, Karaikudi, Tamil Nadu, India.

Ms.M.Muthumari, Research Assistant Department of Fine Arts, Alagappa University, Karaikudi, Tamil Nadu, India.

Mr.P.Avanthraj, Teaching Assistant, Department of Fine Arts, Alagappa University, Karaikudi, Tamil Nadu, India. 